\title{
Obesity communication among patients by health professionals: Findings from the Weight Care Project
}

\author{
S. Anne Moorhead ${ }^{1 \#}$, Vivien E. Coates ${ }^{2}$, Alison M. Gallagher ${ }^{3}$, Geraldine Nolan $^{4}$, \\ Kathy Murphy ${ }^{5}$, Diane E. Hazlett ${ }^{1}$ \\ ${ }^{1}$ School of Communication, University of Ulster, Shore Road, Newtownabbey, Northern Ireland; \\ \#Corresponding Author: a.moorhead@ulster.ac.uk \\ ${ }^{2}$ School of Nursing, University of Ulster, Coleraine, Northern Ireland/Western Health and Social Care Trust, \\ Londonderry, Northern Ireland \\ ${ }^{3}$ Northern Ireland Centre for Food and Health, School of Biomedical Sciences, University of Ulster, Coleraine, Northern Ireland \\ ${ }^{4}$ Department of Health Promotion, National University of Ireland, Galway, Galway Republic of Ireland \\ ${ }^{5}$ School of Nursing, National University of Ireland, Galway, Galway Republic of Ireland
}

Received 13 June 2013; revised 15 July 2013; accepted 1 August 2013

Copyright (C) 2013 S. Anne Moorhead et al. This is an open access article distributed under the Creative Commons Attribution License, which permits unrestricted use, distribution, and reproduction in any medium, provided the original work is properly cited.

\section{ABSTRACT}

Obesity is on the increase worldwide and is a major global public health problem. In an increasingly obesogenic environment, it's important that health professionals are equipped to identify and address obesity issues within their clinical practice. As part of the Weight Care Project, the aim of this study was to explore the obesity-related communication issues for primary care and community-based health professionals. The study design was a quantitative survey, which was completed by 382 primary care and community-based health professionals across Northern Ireland and Republic of Ireland working with adults and children. Key findings included that the majority of the health professionals (86\%) recognized having a role in giving obesity advice, acknowledged that in clinical practice communication of obesity messages is both complex and challenging (81\%), and reported difficulty in sensitively addressing obesity issues (27\%). The health professionals surveyed stated that they communicate obesity messages to their patients using a range of different methods, mainly verbally to individuals, leaflets and factsheets. Numerous benefits of communicating obesity messages were reported; the main one was interacting with patients to build trust. Identified barriers to commu-

\footnotetext{
*Conflict of interest: The authors declare no conflict of interest.
}

nication were: limited time in patient consultations, restricted access to appropriate information, and not sure where to access appropriate resources. Communication needed be reported by the health professionals included provision of greater resources, more information on obesity management and prevention, followed by health communication training, and clear and consistent messages. Significant differences were observed, including significantly much younger health professionals considered their role to provide obesity advice $(P=0.025)$. It is clear from this study that health professionals view as important the need to be given information on "what" and "how" to communicate with their patients on obesity. This study highlights that health professionals need continued support to enable them to effectively address weight-related issues in a sensitive manner that is acceptable to the patient.

Keywords: Obesity; Communication; Health Professionals; Patients

\section{INTRODUCTION}

Obesity represents a major public health problem worldwide, and causes are widely recognized as multifactorial, including individual choice and lifestyle (mainly diet and physical activity) along with environmental influences [1,2]. Prevalence of obesity globally has in- 
creased and nearly doubled since 1980 , with $65 \%$ of the world's population residing in countries where mortality rates are higher due to overweight/obesity than underweight. Obesity has reached epidemic proportions globally, with at least 2.8 million people dying each year as a result of being overweight or obese; however, it is preventable [2].

Public education on weight management is a shared responsibility, and there is a need to raise public awareness of obesity and its health-related consequences [3]. The current information on diet and nutrition is complex and often confusing to the public [4]. As health professionals are in contact with patients, they have opportunities to communicate effective obesity messages and to discuss any weight management issues with their patients. There is evidence to support a role for primary healthcare professionals in the management of obesity and overweight [5]. In addition, a recent study reported that practice nurses within primary care have confidence in their own communication skills and ability to build rapport with patients [6].

Communication in healthcare is paramount, with effective communication clearly linked with positive health outcomes [7]. One of the main reasons for patients' complaints within different global healthcare systems is poor communication between health professionals and patients [7]. It is recommended that experts in communication should assist health professionals in the development of accurate and effective weight-related guidelines [8]. Although there is increasing research in obesity communication, the evidence is limited. It has been reported that communication is a powerful tool for helping patients recognize that being overweight impacts upon health [9]. However, communicating accurate information about weight management is difficult because there are no simple messages [10]. While health professionals caring for children and adolescents are in a key position to promote behavioral and environmental changes, there has been reported confusion regarding various issues including communication with the family about the impact of overweight/obesity [11]. A study with adolescents concluded that appropriate messages could be conveyed through targeted information, education, and communication strategies to complement medical and health care services, which are available, accessible, and acceptable [12]. Literature has shown that clear obesity communication is required for obese pregnant women [13-15]. As pregnant women who are obese are sensitive of their size, the interactions with health professionals and others that they encounter may increase distress $[13,16]$. It has been recommended that communication strategies about care should be clear and honest, and conveyed in a sensitive manner [13,14]. Research suggested more communication between health professionals through professional organizations to increase awareness of existing resources, and to enhance access and referral [17]. Over the last number of years, there were repeated reports for further research in obesity communication [4,18-22].

In relation to communication, it is important to consider the content and delivery of the messages [23]. From the existing research on obesity communication, the content of the message relating to obesity needs to be accurate, appropriate, clear and honest [13,14], which is available, accessible, and acceptable [12] and delivered in a sensitive manner $[13,14]$. Health professionals discussing weight issues with patients can be similar to "breaking bad news" [7], as they are unaware how the patient will respond to the fact that that are overweight or obese, and then to provide appropriate support and guidance, as required. Problems have been reported in communicating between health professionals and patients and also parents such as misunderstanding, define roles and responsibilities, emotion, lack of parent and patient motivation, lack of support services or resources, which are barriers for health professionals' involvement in obesity communication [21,24-27]. Thus, the focus should be on the importance of communicating scientific knowledge to the stakeholders with a responsibility for addressing obesity including barriers [10].

Literature has clearly indicated that there is the need for high quality communication about obesity between health professionals and patients [4,18-22]. However, there is limited research on the communication methods, barriers and needs among a general patient populationfrom primary care and community-based health professionals. The Weight Care Project is an all-Ireland study (including both Northern Ireland (NI) and the Republic of Ireland (ROI)) that aimed to explore the current attitudes and skills of primary care and community-related health professionals towards weight management with a view to supporting them to identify, treat and manage the public health challenge of overweight and obesity [28]. As part of the Weight Care Project, the present study aimed to explore the obesity-related communication issues for primary care and community-based health professionals in NI and ROI.

The theoretical underpinning of this study is Prochaska \& DiClemente's Transtheoretical Model of Change known as the Stages of Change Model [29] and sociological theories such as Bourdieu [30]. The core constructs of the Transtheoretical Model of Change are the processes of change, decisional balance, self-efficacy, and temptation. As part of the processes of change, the covert and overt activity that people use to progress through the stages, one of the ten processes as explained by Prochaska, is the helping relationship (supporting) [29], as the health professional supports the patient in weight loss and management. In addition to the Tran- 
stheoretical Model of Change, sociological theories contribute to the understanding of obesity communication, such as Bourdieu's theoretical framework, based on social and cultural analysis [30]. This current study provides an important stage in increasing our understanding of the obesity-related communication issues for health professionals working within primary care and community-based settings, in order to contribute to effective communication strategies in obesity prevention.

\section{METHODS}

The study design was a quantitative survey as part of the Weight Care Project [28]. Participants in the present survey were primary care and community-based health professionals working within four target settings throughout NI and ROI, namely within 1) primary care (i.e. general practitioners (GPs) and practice nurses); 2) community (i.e. public health nurses involved with postnatal home and clinic visits and developmental checks); 3) schools (i.e. public health nurses aligned with schools); or 4) within the workplace (i.e. occupational health nurses). The total population of primary care and community-based practitioners, i.e. nurses working in the community and primary care and also GPs in Ireland (NI \& ROI) was approximately 8227 in 2008-2011 [31-38]. From previous research, the response rate for online surveys with health professionals was approximately 50\% [39]. Given a confidence level of $95 \%$ and a confidence interval of \pm 5 , an overall sample size of 364 was required to give a sample of primary care and community-based practitioners.

Recruitment of participants was via advertisements/ articles published in relevant professional organizations/ associations' newsletter/bulletin/website inviting health professionals to participate in this study. Postgraduate nursing programs at the two participating Universities in Ireland (one in NI and one in ROI) and the Royal College of Nursing, Belfast were also targeted. In addition, researchers attended numerous relevant meetings/conferences/events throughout all the island of Ireland, and invited the health professionals within the target groups to complete the questionnaire. The Weight Care Project's website acted as a point of contact and as a source of information about this survey, and assisted with recruitment and information for prospective participants. The inclusion criteria were: participants currently employed in a clinical area within one of the target settings (as reported by the participants), and willing to participate in the study. All participants provided informed consent. The exclusion criterion was not being able to provide informed consent.

The questionnaire explored communication issues around tackling obesity and these were divided into five sections, namely: communication experiences, methods, benefits, barriers, and needs. Questions were based on the existing available literature and relevant theories (as cited above). There were a number of questions/statements for each of these sections, and examples were: "I don't feel it is my role to give obesity advice" (experiences), "Which methods do you use to communicate on obesity to your patients?" (methods), "What are the benefits in communicating on obesity to your patientsInteracting with patients results in obtaining further useful information?" (benefits), "What are the barriers in communicating on obesity to your patients - restricted access to appropriate information" (barriers), and "I need further information on obesity prevention" (needs). The questions were presented as statements, and the participants were asked to indicate the level of agreement on a five-point scale, namely: strongly disagree, disagree, neutral, agree and strongly agree.

A pilot ( $n=30$ health professionals) was conducted to determine the feasibility of the survey in terms of the questions and timing. Different participants completed the pilot and main survey. The findings indicated that the survey was appropriate for the research aim and following minor changes such as formatting, and it was finalized.

The questionnaire was available either via hard copy or online, hosted on the Weight Care Project's website via the leading University's website. If the health professionals did not have access to the internet and were willing to participate in this project, a hard copy of the questionnaire was provided. The survey took respondents approximately 10 - 15 minutes to complete. As this was an all-Ireland study, it was approved by seven ethical/ research governance committees throughout the island of Ireland (NI \& ROI).

Data were analyzed using SPSS version 19. Summary data analysis including frequencies and descriptive statistics (as appropriate) was conducted for all the variables. To determine if there were significant differences among the variables, influential statistics were conducted. As data was treated as nominal and ordinal, non-parametric tests were conducted. Data for the communication experiences, methods, benefits, barriers and needs were statistically analyzed by region (NI or ROI), health professional group (primary care, community, schools, or workplace), age group, gender, years of clinical experience, and BMI of the health professionals (determined from self-report height and weight information), using chi-square, Spearman Correlations, and Mann-Whitney and Kruskal-Wallis tests, as appropriate.

\section{RESULTS}

\subsection{Participants' Demographics}

In total, 382 health professionals completed the survey, 
and the participants' demographics are presented in Table 1. The survey was distributed in electronic and paper versions. The paper version was completed by 116 health professionals, and the electronic version was distributed to 371 health professionals and 266 returned the survey giving a response rate of $72 \%$. The total sample of 382 met the recruitment target $(n=364)$ achieving approximately $5 \%$ of the target sample size of primary care and community-based health professionals (nurses and GPs) from 8227 in Ireland (ROI and NI). This sample comprised of health professionals from the following settings: $n=149$ primary care (i.e. $n=46$ GPs and $n=103$ practice nurses); $n=115$ community (i.e. public health nurses/community nurses); $n=74$ school (i.e. school nurses); and $n=44$ workplace (i.e. occupational health nurses). From the 364 professionals, 110 were from NI and 272 from the ROI.

\subsection{Communication Experiences}

The health professionals surveyed reported a range of experiences when communicating obesity messages (Table 2), with $86 \%$ reporting that they have a role in giving obesity advice, $85 \%$ communicating risks/hazards, and providing information on obesity prevention (86\%) and management (82\%) to patients, when required. The response from patients were reported to be mainly positive, as $61 \%$ of the health professionals stated that their patients receive their advice/information on obesity favorably, while $18 \%$ stated that patients don't appreciate/ adhere to their advice/information on obesity. It was reported that $65 \%$ of health professionals identify patients who are overweight/obese and then provide advice/information on obesity prevention. The health professionnals reported difficulty in knowing whether to address obesity, fitness and lifestyle issues (18\%), difficulty in sensitively addressing obesity issues (27\%), and that communication of obesity messages is both complex and challenging (81\%). It was found that significantly much younger health professionals considered their role to provide obesity advice ( $P=0.025$, Spearman Correlation),

Table 1. Gender, age, years of clinical experience and self-reported BMI of the survey respondents $(n=382)$.

\begin{tabular}{|c|c|c|c|c|c|}
\hline \multirow{3}{*}{ Characteristic } & \multicolumn{4}{|c|}{ Setting } & \multirow{3}{*}{ Total } \\
\hline & Primary $^{\mathrm{a}}$ & Community $^{\mathbf{b}}$ & Schools $^{c}$ & Workplace $^{\mathrm{d}}$ & \\
\hline & \multicolumn{4}{|c|}{ Number (\%)/Mean (SD) } & \\
\hline \multicolumn{6}{|l|}{ Gender } \\
\hline \multicolumn{6}{|l|}{ Total } \\
\hline Female & $146(97 \%)$ & 109 (95\%) & 73 (99\%) & 37 (93\%) & $365(96 \%)$ \\
\hline Male & $4(3 \%)$ & $6(5 \%)$ & $1(1 \%)$ & $6(7 \%)$ & $17(4 \%)$ \\
\hline \multicolumn{6}{|l|}{ NI } \\
\hline Female & 38 (97\%) & $32(89 \%)$ & $17(100 \%)$ & $14(78 \%)$ & $101(92 \%)$ \\
\hline Male & $1(3 \%)$ & $4(11 \%)$ & $0(0 \%)$ & $4(12 \%)$ & $9(8 \%)$ \\
\hline \multicolumn{6}{|l|}{ ROI } \\
\hline Female & 108 (97\%) & 77 (97\%) & 56 (98\%) & 23 (92\%) & 264 (97\%) \\
\hline Male & $3(3 \%)$ & $2(3 \%)$ & $1(2 \%)$ & $2(8 \%)$ & $8(3 \%)$ \\
\hline \multicolumn{6}{|l|}{ Age (years) } \\
\hline Total & $44.0(9.0)$ & $43.4(9.1)$ & $43.2(9.5)$ & $44.2(8.5)$ & $43.7(9.0)$ \\
\hline NI & $48.2(7.1)$ & $45.1(10.0)$ & $47.6(7.5)$ & $45.2(9.4)$ & $46.6(8.6)$ \\
\hline ROI & $42.6(9.1)$ & $42.6(8.6)$ & $41.9(9.7)$ & 43.5 (7.9) & 42.5 (8.9) \\
\hline \multicolumn{6}{|c|}{ Clinical experience (years) } \\
\hline Total & $20.6(9.3)$ & $17.6(11.6)$ & $17.7(10.5)$ & $20.9(9.3)$ & $19.2(10.3)$ \\
\hline NI & $23.9(8.8)$ & $22.0(10.3)$ & $25.1(7.2)$ & $21.0(10.9)$ & $23.3(9.5)$ \\
\hline ROI & $19.5(9.2)$ & $15.5(11.7)$ & $15.7(10.4)$ & $20.8(8.3)$ & $17.7(10.3)$ \\
\hline \multicolumn{6}{|c|}{ Self-reported BMI $\left(\mathrm{kg} / \mathrm{m}^{2}\right)$} \\
\hline Total & $26.4(11.1)$ & $25.7(4.5)$ & $25.4(4.2)$ & $25.5(4.8)$ & $25.9(7.7)$ \\
\hline NI & $27.3(5.7)$ & $25.5(4.3)$ & $26.0(5.3)$ & $26.6(3.0)$ & $26.4(4.8)$ \\
\hline ROI & $26.2(12.3)$ & 25.8 (4.6) & $25.2(3.8)$ & 24.7 (5.6) & 25.8 (8.6) \\
\hline
\end{tabular}

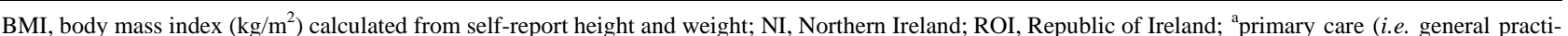
tioners (GPs) and practice nurses); ${ }^{b}$ community (i.e. public health nurses involved with postnatal home and clinic visits and developmental checks); ${ }^{\mathrm{c}}$ schools (i.e. public health nurses aligned with schools); or "within the workplace (i.e. occupational health nurses). 
Table 2. Experiences of health professionals communicating obesity messages $(n=382)$.

\begin{tabular}{|c|c|c|c|c|c|}
\hline Statement & $\begin{array}{c}\text { Strongly } \\
\text { disagree (\%) }\end{array}$ & $\begin{array}{l}\text { Disagree } \\
(\%)\end{array}$ & $\begin{array}{c}\text { Neutral } \\
(\%)\end{array}$ & $\begin{array}{c}\text { Agree } \\
(\%)\end{array}$ & $\begin{array}{l}\text { Strongly } \\
\text { agree (\%) }\end{array}$ \\
\hline "I don't feel it is my role to give obesity advice" & 52 & 34 & 8 & 4 & $2^{*}$ \\
\hline "I have difficulty in knowing whether to address obesity fitness to lifestyle issues" & 34 & 32 & 16 & 16 & 2 \\
\hline "I find it difficult to sensitively address obesity issues" & 24 & 35 & 14 & 22 & 5 \\
\hline $\begin{array}{c}\text { "I identify my patients who are overweight/obese and provide advice/information } \\
\text { on weight loss" }\end{array}$ & 7 & 9 & 19 & 44 & 21 \\
\hline "When needed I give my patients advice/information on obesity prevention" & 6 & 2 & 6 & 60 & $26^{*}$ \\
\hline "When needed I give my patients advice/information on obesity management" & 7 & 2 & 9 & 56 & $26^{*}$ \\
\hline "When needed I communicate risks/hazards" & 4 & 2 & 9 & 55 & 30 \\
\hline "My patients receive my advice/information on obesity favorably" & 5 & 8 & 26 & 48 & 13 \\
\hline "My patients don't appreciate/adhere to my advice/information on obesity" & 11 & 29 & 42 & 16 & 2 \\
\hline "Communication of obesity messages is complex and challenging" & 3 & 5 & 11 & 42 & $39^{*}$ \\
\hline
\end{tabular}

*Significantly increased with increasing age of the health professionals $(P<0.05$; Spearman Correlations).

but significantly much older people provide advice/information on obesity prevention $(P=0.006$, Spearman Correlation) and management $(P=0.014$, Spearman Correlation), when required, and also agree that the communication of obesity messages is complex and challenging ( $P=0.001$, Spearman Correlation).

\subsection{Communication Methods}

Health professionals reported that they communicate obesity messages to their patients using a range of different methods (Table 3). The most frequently reported communication methods were "verbally to individuals" (94\%) followed “leaflets" (82\%) and “fact sheets" (76\%). No significant differences were found between the reported communication methods by region (NI vs. ROI), across the health professional groups (primary care, community, schools, and workplace), by age group, gender, years of clinical experience, or BMI (self-reported) of the health professionals.

\subsection{Communication Benefits}

Health professionals stated numerous benefits of communication of obesity (Table 4). The majority of respondents reported that they were "interacting with patients builds trust" (95\%), "interacting with patients increases their knowledge of obesity" (94\%), and "interacting with patients increases their awareness of obesity" (93\%; Table 4). There were no significant differences found for communication benefits.

\subsection{Communication Barriers}

The main barriers to communication identified by health professionals were "limited time in patient consultations" (74\%), "restricted access to appropriate information" (57\%), and being "unsure where to get ap- propriate resources" (57\%). Significantly more nurses working in the area of public health reported barriers than their colleagues (practice nurses and GPs) in primary care for "limited time in patient consultations" $(P=$ 0.023, Mann Whitney), "restricted access to appropriate information" ( $P=0.007$, Mann Whitney), and being "unsure where to get appropriate resources" ( $P=0.005$, Mann Whitney). The barriers "restricted access to appropriate information" ( $P=0.004$, Mann Whitney) and being "unsure where to get appropriate resources" ( $P=$ 0.025 , Mann Whitney) were significantly greater in the ROI than in NI. Thus it is significantly easier to access and also know how obtain appropriate information in NI than in the ROI.

\subsection{Communication Needs}

The main reported communication needs by health professionals were more resources (85\%), more information on obesity management (85\%) and prevention (82\%), followed by health communication training (61\%) and clear and consistent messages (56\%; Table 5). A total of $38 \%$ of health professionals reported that they had received health communication related training. It was found that significantly much older health professionals reported the need for further information on obesity prevention ( $P=0.021$, Spearman Correlations), obesity management ( $P=0.024$, Spearman Correlations) and received health communication related training $(P=0.031$, Spearman Correlations). Health professionals from ROI were more likely to agree that there was a need for clear and consistent messages than those based in NI $(P=$ 0.042, Mann Whitney).

\section{DISCUSSION}

This is the first study that has explored a range of the 
Table 3. Communication methods reported by the health professionals $(n=382)$.

\begin{tabular}{|c|c|c|c|c|c|}
\hline Method & Never (\%) & Rarely (\%) & Sometimes (\%) & Frequently (\%) & Always (\%) \\
\hline Verbally_-individual & 3 & 3 & 23 & 42 & 29 \\
\hline Verbally_groups & 60 & 18 & 10 & 9 & 3 \\
\hline Videos/DVDs & 71 & 19 & 6 & 2 & 2 \\
\hline Leaflets & 11 & 7 & 30 & 39 & 13 \\
\hline Fact sheets & 16 & 8 & 31 & 34 & 11 \\
\hline Books & 53 & 24 & 12 & 7 & 4 \\
\hline Website addresses & 34 & 17 & 25 & 20 & 4 \\
\hline Media such as TV, radio & 53 & 23 & 15 & 6 & 3 \\
\hline Social media tools such as Facebook, Twitter & 77 & 16 & 5 & 1 & 1 \\
\hline
\end{tabular}

Table 4. Communication benefits reported by the health professionals $(n=382)$.

\begin{tabular}{|c|c|c|c|c|c|}
\hline Statement & $\begin{array}{c}\text { Strongly } \\
\text { disagree (\%) }\end{array}$ & $\begin{array}{c}\text { Disagree } \\
(\%)\end{array}$ & $\begin{array}{c}\text { Neutral } \\
(\%)\end{array}$ & $\begin{array}{c}\text { Agree } \\
(\%)\end{array}$ & $\begin{array}{c}\text { Strongly } \\
\text { agree (\%) }\end{array}$ \\
\hline "Interacting with patients results in obtaining further useful information" & 0 & 0 & 12 & 48 & 40 \\
\hline "Interacting with patients results in their greater adherence to treatment" & 0 & 1 & 7 & 54 & 38 \\
\hline "Interacting with patients builds trust" & 0 & 2 & 3 & 56 & 39 \\
\hline "Interacting with patients results in positive health outcomes" & 0 & 2 & 13 & 51 & 34 \\
\hline "Interacting with patients increases their awareness of obesity" & 0 & 0 & 7 & 57 & 36 \\
\hline "Interacting with patients increases their knowledge of obesity" & 0 & 0 & 6 & 58 & 36 \\
\hline "I identify individual patient weight management needs and risk factors" & 3 & 9 & 26 & 39 & 23 \\
\hline "Providing information to patients aids them to make informed decisions" & 0 & 3 & 7 & 51 & 39 \\
\hline
\end{tabular}

Table 5. Communication needs reported by the health professionals $(n=382)$.

\begin{tabular}{cccccc}
\hline Statement & Strongly disagree (\%) & Disagree (\%) & Neutral (\%) & Agree (\%) & Strongly agree (\%) \\
\hline $\begin{array}{c}\text { "I need further information on obesity prevention" } \\
\text { "I need further information on obesity management" }\end{array}$ & 2 & 6 & 10 & 51 & $\mathbf{3 1}^{*}$ \\
"I need more obesity resources" & 2 & 6 & 7 & 52 & $\mathbf{3 3}^{*}$ \\
"I need health communication training" & 2 & 5 & 8 & 51 & 34 \\
"There is a need for clear and consistent messages" & 1 & 15 & 18 & 37 & 24 \\
\hline
\end{tabular}

*Significantly increased with increasing age of the health professionals $\left(P<0.05\right.$, Spearman Correlations); ${ }^{* *}$ Health professionals from the Republic of Ireland agreed significantly more than those in Northern Ireland $(P<0.001 ;$ Mann Whitney).

obesity-related communication issues among primary care and community-based health professionals. Overall, health professionals surveyed reported having a role in providing obesity communication to their patients, and recognized that these communications need to be clear, consistent accessible, and well-resourced (including information and training).

The majority of health professionals surveyed (86\%) reported having a role in giving obesity advice, thus acknowledging their contribution to and willingness to be proactive in reducing the epidemic of obesity by providing advice to their patients. This supports a previous study, which highlighted the need for health professionals to communicate accurate and effective weight-related guidelines [8]. Previous research strongly supports a role for primary healthcare professionals in the management of obese and overweight individuals [5]. It is now recognized that many adults and parents do not recognize or perceive that a weight problem in their child (particularly when they themselves are overweight/obese) and thus 
health professionals can use opportunities in consultations to increase awareness that they or their children have excess weight [40]. One potentially positive finding in the present study is that younger health professionals were more likely to report a role in providing advice to reduce obesity; possibly indicating that more health professionals in the future will provide obesity advice to their patients. This highlights the continued need to include health communication training in courses for health professionals. Overall, health professionals surveyed were active in providing obesity advice as the majority reported to provide information on obesity prevention and management to patients, when required. Whilst patients were mainly positive (61\%), some reported (18\%) that patients did not appreciate or adhere to theadvice and information they receive [from health professionals] on obesity. This suggests that the majority of patients are willing to take advice on obesity from health professionals, thus endorsing the need and role of health professionals in obesity communication but further education is needed among patients.

The health professionals reported that they communicate obesity messages to their patients using a range of different methods. However, the majority of methods were traditional in nature such as verbal communication, provision of leaflets or fact sheets, and these have been reported as the common methods in communicating among health professionals [7]. Despite recent increases in the usage of social media [41], only a few (7\%) health professionals reported engagement with social media for delivering health messages. A recent systematic review reported that health professionals' use of social media to communicate with patients was limited, and suggested they may require training to fully maximize use of social media within health care settings. It is likely that utilizetion of social media for these purposes may increase in the future as technological advances and more opportunities arises [42].

Health professionals in this survey stated numerous benefits of communicating with patients about their body weight status. They reported that communicating obesity messages to their patients leads to building of patientpractitioner trust, and increases patients' knowledge and awareness of obesity. This is important as patients need to be aware of the health risks of obesity, and equally since behavior change is difficult, developing a trusting relationship with the health professionals is essential for behavior change leading to weight loss and maintenance [7].

In this survey, health professionals reported difficulty in knowing whether to address obesity, fitness and lifestyle issues, and that communication of obesity messages is both complex and challenging. These are valid issues, as weight management matters are sensitive and chal- lenging to address $[13,14]$. For health professionals to maximize their role, all of these difficulties need to be minimized. Potential methods include training the health professionals, and they reported in this current survey that they would like further training. Health professionals surveyed reported barriers to communication, as there is limited time in patient consultations, restricted access to appropriate information, and being unsure where to get appropriate resources; which are practicalities that need to be minimized [10]. These findings support previous research as the barriers have been reported for communication in health care $[43,44]$, and also in communicating on obesity $[25,45]$.

The main reported communication needs by the health professionals were more resources (85\%), and more information on obesity management and prevention, followed by health communication training, and clear and consistent messages. These needs can be met by existing training together with opportunities for provision of easily accessible resources such as online programs. As there is a reported need for clear and consistent messages, relevant organizations need to collaborate to provide simpler, clear, consistent messages for health professionals to forward to their patients. This finding supports previous research among children and pregnant women populations for the need for clear obesity communication [13-15], which is honest, conveyed in a sensitive manner [13,14], available, accessible, and acceptable [12]. Like [46] stated four activities that can contribute to the communication between patient and practitioner, these are: asking nonjudgmental questions; listening carefully; working with the patient and family members (as appropriate) to set realistic achievable goals for behavior change; and involving the patient in active problem solving.

The findings from the present survey support the theoretical underpinning of this study, i.e. Transtheoretical Model of Change (or Stages of Change Model) [29] and sociological theories such as Bourdieu [30]. On the basis of the Stage of Change Model, the health professional provides motivation, information and confirmation at the right times to facilitate and accelerate the behavior change process [19]. As patients need support to change their lifestyle to promote weight loss and maintaince, and health professionals are willing to provide this support (helping relationship) in the form of advice. Individuals who are overweight or obese may lack self-esteem and conscious of their self-image, thus health professionals may need to be aware of the patients' non-verbal and as well as verbal cues. Social-related factors such as stigma, need to be considered and addressed, as health professionals need resources and training on how and when to approach and address weight-related issues sensitively. As the participants in this survey were health profession- 
als working in primary care and community, these settings provides opportunities to address obesity-related issues in conjunction to the care of other conditions, such as diabetes.

From this study, the implications for practice are that primary care and community-based health professionals reported that they have a role in communicating obesity messages, thus they are proactive and have an essential role in obesity prevention. However, they are uncertain on "what" and "how" to communicate to their patients on obesity. In relation to the "what", this includes the content of the message, which needs to be accurate, clear and consistent. Such a message provides challenges to health professionals as individuals are different and the message should be tailored to the patient. Health professionals also recognized a need for guidance on "how" to communicate obesity messages, especially on how to address obesity-related issues in a sensitive manner that is acceptable to the patient. Potential suggestions could be to address the weight of the patients as part of the management of other chronic conditions such as diabetes, as obesity is a risk factor for many chronic conditions, and also by health professionals building a trusting relationship with the patients before addressing any weight matters. Health professionals need support on how to "start the conversation on obesity" including when and where, advice on the awareness of nonverbal cues and where to seek additional support, when required.

The limitations of this study were that the health professionals who participated in this survey were mainly nurses with a few GPs, and those who volunteered for this study were a self-selected sample, thus may have an interest in obesity that may be a bias. This survey was quantitative but additional qualitative research would provide in-depth information on the barriers to obesity communication. It has been acknowledged that communication alone has not been, and will not be, sufficient for individuals to adopt the behavioral changes endorsed by experts. As broad environmental interventions with individual skills development will need to be part of the process [47].

Further research in obesity communication is required to explore methods to minimize the barriers, and meeting the reported needs of health professionals. Although the findings produced interesting issues from the quantitative survey, follow-up qualitative research will be useful with patients, their families and health professionals to explore and provide in-depth information on the barriers to obesity communication such as sensitively, in order to develop a communication strategy for the delivery of obesity messages by health professionals to patients, that is acceptable to both health professionals and patients. This research could be developed further among different population groups such as morbidly obese patients, and a greater range of different health professional groups.

\section{CONCLUSIONS}

This study contributes to the existing body of literature on obesity communication that overall, primary care and community-based health professionals on the island of Ireland (NI \& ROI) reported that they have a role in communicating obesity messages but they also reported that they require clear consistent and accessible messages on obesity and further resources, including information and training in addressing obesity issues among their patients. Although this study was conducted in Ireland, these conclusions may apply to health professionals elsewhere given that obesity is a public health issue worldwide.

It is clear from this study that health professionals view as important the need to be given information on "what" and "how" to communicate with their patients on obesity, that is what the message should be and how should it be delivered that is acceptable and effective for the patient. Health professionals need to be supported and provided with accurate, clear and consistent messages, and guidance on delivering the advice in a sensitive manner to their patients that is acceptable. Further research is required to determine the most acceptable ways for health professionals to address obesity sensitively with their patients.

\section{ACKNOWLEDGEMENTS}

The authors would like to thank Evie Gardiner (health statistician), University of Ulster for guidance on the statistical analysis. This research was funded by safefood, the Food Safety Promotion Board, under Grant No. 08/2009.

\section{REFERENCES}

[1] International Obesity Task Force. (2013) Obesity. http://www.iaso.org/iotf/

[2] World Health Organization. (2013) Obesity and overweight. http://www.who.int/mediacentre/factsheets/fs311/en/

[3] Chan, S.P., Chui, W.C., Lo, K.W., Huang, K.C., Leyesa, N.D., Lin, W.Y., Mirasol, R.C., Robles, Y.R., Tey, B.H. and Paraidathathu, T. (2012) Consensus statement: Appropriate consumer education and communication programs for weight-loss agents in Asia. Asia-Pacific Journal of Public Health, 24, 641-649. doi:10.1177/1010539511402189

[4] Viswanath, K. and Bond, K. (2007) Social determinants and nutrition: Reflections in the role of communication. Journal of Nutrition Education and Behavior, 39, S20S24. doi:10.1016/j.jneb.2006.07.008

[5] Harvey, E.L., Glenny, A.M., Kirk, S.F.L. and Summerbell, C.D. (2001) Improving health professionals' management and the organisation of care for overweight and obese 
people. The Cochrane Database of Systematic Reviews, 2, CD000984.

[6] Nolan, C., Deehan, A., Wylie, A. and Jones, R. (2012) Practice nurses and obesity: Professional and practicebased factors affecting role adequacy and role legitimacy. Primary Health Care Research \& Development, 13, 353363. doi:10.1017/S1463423612000059

[7] Berry, D. (2007) Health Communication: Theory and Practice. Open University Press, Poland.

[8] Boylan, S. Louie, J. C. Y. and Gill, T. P. (2012) Consumer response to healthy eating, physical activity and weightrelated recommendations: A systematic review. Obesity Reviews, 13, 606-617. doi:10.1111/j.1467-789X.2012.00989.X

[9] Durant, N.H., Bartman, B., Person, S.D., Collins, F. and Austin, S.B. (2009) Patient provider communication about the health effects of obesity. Patient Education and Counseling, 75, 53-57. doi:10.1016/j.pec.2008.09.021

[10] Jebb, S.A., Lang, R. and Penrose, A. (2003) Improving communication to tackle obesity in the UK. Proceedings of the Nutrition Society, 62, 577-581. doi:10.1079/PNS2003278

[11] Carrel, A.L. and Allen, D.B. (2005) Off the growth curve: The challenge of childhood obesity. WMJ, 104, 32-37.

[12] Chhabra, S. (1992) Health of adolescents. Indian Journal of Maternal \& Child Health, 3, 1-3.

[13] Furber, C.M. and McGowan, L. (2011) A qualitative study of the experiences of women who are obese and pregnant in the UK. Midwifery, 27,437-444. doi:10.1016/j.midw.2010.04.001

[14] Heslehurst, N., Moore, H., Rankin, J. Ells, L.J., Wilkinson, J.R. and Summberbell, C.D. (2011) How can maternity services be developed to effectively address maternal obesity? A qualitative study. Midwifery, 27, e170-e177. doi:10.1016/j.midw.2010.01.007

[15] Tan, T. and Sia, A.T. (2011) Anesthesia considerations in the obese gravida. Seminars in Perinatology, 35, 350-355. doi:10.1053/j.semperi.2011.05.021

[16] Furness, P.J., McSeveny, K., Arden, M.A., Garland, C. Dearden, A.M. and Soltani, H. (2011) Maternal obesity support services: A qualitative study of the perspectives of women and midwives. BMC Pregnancy \& Childbirth, 11, 69. doi:10.1186/1471-2393-11-69

[17] Wethington, H.R., Sherry, B. and Polhamus, B. (2011) Physician practices related to use of BMI-for-age and counseling for childhood obesity prevention: A cross-sectional study. BMC Family Practice, 12, 80. doi:10.1186/1471-2296-12-80

[18] Himmel, W., Stolpe, C. and Kochen, M. (1994) Information and communication about overweight in family practice. Family Practice Research Journal, 14, 339-351.

[19] Koster, F.R.T., Verheijden, M.W. and Baartmans, J.A. (2005) The power of communication. Modifying behavior: Effectively influencing nutrition patterns of patients. European Journal of Clinical Nutrition, 59, S17-S22. doi:10.1038/sj.ejcn.1602169

[20] Sandberg, H. (2005) Information and communication in society. Acta Paediatrica Supplement, 94, 38-39. doi:10.1080/08035320510035285

[21] Mikhailovich, K. and Morrison, P. (2007) Discussing childhood overweight and obesity with parents: A health communication dilemma. Journal of Child Health Care, 11, 311-322. doi:10.1177/1367493507082757

[22] Perrin, E.M., Skinner, A.C. and Steiner, M.J. (2012) Parental recall of doctor communication of weight status: national trends from 1999 through 2008. Archives of Pediatrics \& Adolescent Medicine, 166, 317-322. doi:10.1001/archpediatrics.2011.1135

[23] Hargie, O. (2011) Skilled Interpersonal Communication: Research, theory and practice. 5th Edition, Routledge, London.

[24] Fallowfield, L. and Jenkins, V. (2004) Communicating sad, bad, and difficult news in medicine. The Lancet, $\mathbf{3 6 3}$, 312-319. doi:10.1016/S0140-6736(03)15392-5

[25] Maryon-Davis, A. (2005) Weight management in primary care: how can it be made more effective? Proceedings of the Nutrition Society, 64, 97-103. doi:10.1079/PNS2004414

[26] Sheldon, L.K., Barrett, R. and Ellington, L. (2006) Difficult communication in nursing. Journal of Nursing Scholarship, 38, 141-147. doi:10.1111/j.1547-5069.2006.00091.x

[27] Freedman, M.R. and Stern, J.S. (2004) The role of optimal healing environments in the management of childhood obesity. Journal of Alternative and Complementary Medicine, 10, S231-S244. doi:10.1089/1075553042245863

[28] Moorhead, S.A., Coates, V., Hazlett, D., Gallagher, A.M., Murphy, K., Nolan, G. and Dinsmore, J. (2011) Weight Care Project: Health professionals' attitudes and ability to assess body weight status-Study protocol. BMC Public Health, 11, 202. doi:10.1186/1471-2458-11-202

[29] Prochaska, J.O. and DiClemente, C.C. (1984) The transtheoretical approach: Towards a systematic eclectic framework. Dow Jones Irwin, Homewood.

[30] Bourdieu, P. (1977) Outline of a theory of practice. Cambridge University Press, Cambridge. doi:10.1017/CBO9780511812507

[31] Medical Council of Ireland. (2008) Registration Information. http://www.medicalcouncil.ie/

[32] Nursing and Midwifery Council. (2008) Statistical analysis of the register 1 April 2007 to 31 March 2008. Nursing and Midwifery Council, Dublin.

[33] Nursing Board. (2008) Nursing figures. http://www.nursingboard.ie/en/homepage.aspx

[34] Northern Ireland Health and Social Care. (2008) Workforce Census 31 March 2008. Department of Health, Social Services and Public Safety, Belfast.

[35] Royal College of General Practitioners, Northern Ireland Office. (2009) GPs registered in 2008 in Northern Ireland. Personal correspondence.

[36] Institute of Community Health Nursing. (2011) Community Nursing. http://www.ichn.ie/

[37] Occupational Health Nurses Association of Ireland (2011) 
Occupational health nurses. Personal Correspondence.

[38] Department of Health, Social Services, and Public Safety. (2010) Fitter future for all, consultation report: Obesity prevention framework for Northern Ireland 2011-2021. Department of Health, Social Services, and Public Safety, Belfast.

[39] Murphy, K. (2007) Nurses’ perceptions of quality and the factors that affect quality care for older people living in long term care setting in Ireland. Journal of Clinical Nursing, 16, 873-884.

doi:10.1111/j.1365-2702.2006.01633.x

[40] Safefood. (2012) Bodyweight perception on the island of Ireland.

http://www.safefood.eu/SafeFood/media/SafeFoodLibrar y/Documents/Publications/Research\%20Reports/Bodyweight-Perception-with-accepted-changes-JC-version-2.p df

[41] Heidelberger, C.A. (2011) Health care professionals' use of online social networks.

http://cahdsu.wordpress.com/2011/04/07/infs-892-healthcare-professionals-use-of-online-social-networks/

[42] Moorhead, S.A., Hazlett, D.E., Harrison, L., Carroll, J.K., Irwin, A. and Hoving, C. A. (2013) New dimension of health care: Systematic review of the uses, benefits, and limitations of social media for health communication. Journal of Medical Internet Research, 15, e85. doi:10.2196/jmir.1933

[43] Prout, H., Butler, C. and Kinnersley, P. (2003) A qualitative evaluation of implementing a randomized controlled trial in general practice. Family Practice, 20, 675-681. doi:10.1093/fampra/cmg609

[44] Nelson, P., Adamson, A. and Moore, H. (2006) Conducting randomized controlled trials in primary care: Lessons from an obesity management trial. British Journal of General Practice, 56, 674-679.

[45] Hiddink, G.J., Hautvast, J.G.A.J. Van Woerkum, C.M.J., Fieren, C.J. and Van't Hof, M.A. (1997) Driving forces and barriers to nutrition guidance and practices of Dutch primary care physicians. Journal of Nutrition Education, 29, 36-41. doi:10.1016/S0022-3182(97)70144-4

[46] Like. (1998) Patient Adherence. The providers guide to quality \& culture. Management Sciences for Health, Boston.

[47] Goldberg, J.P. and Sliwa, S.A. (2011) Communicating actionable nutrition messages: Challenges and opportunities. Proceedings of the Nutrition Society, 70, 26-37. doi:10.1017/S0029665110004714 